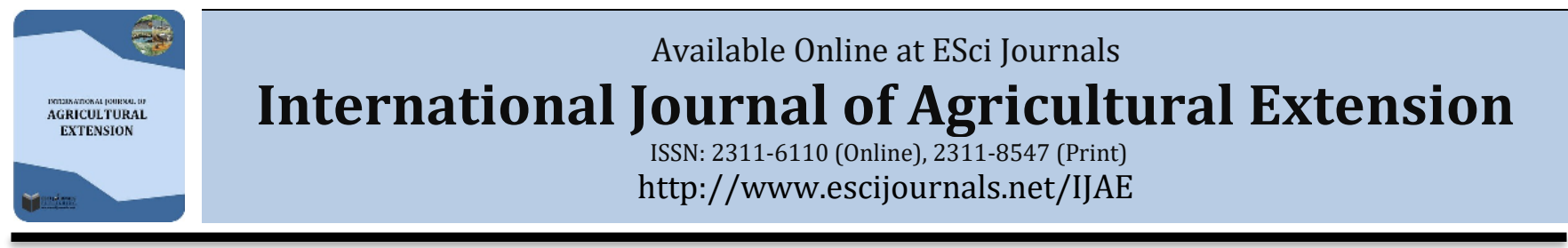

\title{
ASSOCIATIONS BETWEEN SOURCES OF INFORMATION AND ANIMAL HEALTH KNOWLEDGE OF RURAL FARMERS IN CENTRAL ETHIOPIA
}

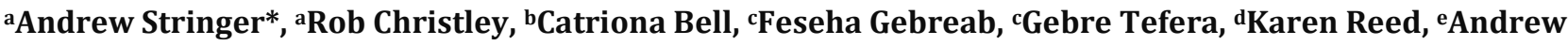 \\ Trawford, aGina Pinchbeck \\ a Institute of Infection and Global Health, University of Liverpool, Liverpool, United Kingdom. \\ ${ }^{b}$ Royal (Dick) School of Veterinary Studies, University of Edinburgh, Roslin, Midlothian, United Kingdom. \\ ${ }^{c}$ College of Veterinary Medicine and Agriculture, Addis Ababa University, Debre Zeit, Ethiopia. \\ ' Spana, 14 John Street, London, United Kingdom. \\ e The Donkey Santuary, Sidmouth, Devon, United Kingdom.
}

\begin{abstract}
A B S T R A C T
This study explored the information sources through which working donkey owners and users in Ethiopia acquire knowledge about donkey health and husbandry practices. Individual interviews, a Participatory Situation Analysis (PSA) and a cross-sectional study with rural farmers were utilised to develop an understanding of the existing sources of information concerning donkey health and husbandry and determine the association with the knowledge of farmers. Numerous sources were utilized by owners for information regarding health and husbandry advice for donkeys. Most owners reported that the sources were unreliable with regards to the information they provided on donkey health and husbandry. Knowledge score of participants increased as the number of information sources contacted increased. Knowledge score also increased with increasing education level, literacy ability and radio access. A significant association between knowledge score and age was identified, with knowledge score decreasing in older individuals. Multilevel linear regression models revealed a number of variables, including formal education level and cattle ownership to be significantly associated with knowledge score. We conclude that a range of factors can affect the knowledge level of an individual concerning donkey health and husbandry, and that individuals with more diverse knowledge sources have higher knowledge scores. The relationship between specific farmer variables and animal health knowledge is complex, and it may be necessary to use different sources and channels to transfer and disseminate information to individuals living in rural Ethiopia.
\end{abstract}

Keywords: Knowledge, information, animal health, donkey, farmer, Ethiopia.

\section{INTRODUCTION}

The effectiveness of extension dissemination routes is one of the major challenges for the development of agriculture worldwide (Msuya et al., 2017; Worku, 2017; Ong'ayo et al., 2016; David \& Samuel 2014; Krishnan \& Patnam 2014; Wale \& Yalew 2007; Tesfaye et al., 2005; Belay \& Abebaw, 2004). A greater understanding of existing formal and informal information sources, and knowledge-transfer networks could potentially improve the development of appropriate extension approaches that facilitate knowledge transfer and innovation adoption

* Corresponding Author:

Email: apstringer@ncsu.edu

(C) 2019 ESci Journals Publishing. All rights reserved.
(Msuya et al., 2017; Tesfaye et al., 2005; Kassa, 2003). Numerous potential sources of information exist for Ethiopian farmers, including government and private extension agents, farmers, Contact Farmers (successful and progressive farmers who become opinion leaders and are utilised in extension programmes), radio programmes, neighbours, relatives, Peasant Association representatives and other social institutions. However, previous studies of agricultural extension in Ethiopia have emphasised the top-down approach to service provision, with the public sector being the main service provider (Agitew et al., 2018; Worku, 2017; Elias et al., 2015; Mogues et al., 2009; Wale \& Yalew, 2007). Tesfaye et al. (2005) identified three key criteria affecting a 
farmer's decision when selecting an information source: accuracy/reliability, timeliness and accessibility. The most important criteria that influenced choice was the accuracy and reliability of the information source, with farmers ranking extension agents first based on these criteria, followed by radio programmes and then fellow neighbours and farmers (Tesfaye et al., 2005).

The number of working equids are increasing in many low-income countries, and their importance is being emphasized by increasing human populations, global economic issues and changing environments (Pritchard, 2010). There are estimated to be 8.4 million donkeys working in Ethiopia (FAO, 2016), and their health and productivity is affected by prevalent parasitic and infectious diseases, and problems associated with inadequate management practices (Stringer et al., 2017; Curran, Feseha \& Smith, 2005; Pritchard et al., 2005). One approach to address these challenges is through the education of owners and communities via the provision of information and the improvement of animal health knowledge, with Tesfaye et al. (2005) identifying a need for increased knowledge delivered through training for Ethiopian farmers.

With the majority of the Ethiopian population living in a rural location and most rural households owning a donkey, this study aimed to identify the information sources through which rural working donkey owners and users in Ethiopia acquire knowledge about donkey health and husbandry practices. Understanding how information is acquired, and what reliability owners place on it, is an important consideration when designing an educational or extension programme. Identification of the sources of information regarding donkey care currently used by Ethiopian working donkey users will be beneficial to non-governmental organisations and government institutions when deciding how best to disseminate information. Information about these networks can be used in generating hypotheses regarding the potential acquisition and diffusion of knowledge for improving animal health.

\section{MATERIALS AND METHODS}

The study utilised two different but complimentary methodological approaches to achieve our proposed aim. Firstly, an individual questionnaire and a group Participatory Situation Analysis (PSA) involving 120 individuals was conducted in eight rural villages. Secondly, a cross-sectional study was administered to 516 rural donkey-owning individuals from 32 villages in central Ethiopia. This mixed-method approach utilised both quantitative and qualitative methodologies to better understand farmer knowledge and experience, and provided a more accurate picture of the situation than could be obtained utilising only a classical quantitative epidemiological approach.

\section{Individual Questionnaire and Group Participatory Situation Analysis (PSA)}

Study Area and Participants: The study was conducted in eight rural villages representing a range of agroecological zones (Supplementary Information 1). Villages were selected from two regions in Ethiopia (Amhara and Oromia) by convenience and were chosen to be approximately representative of other villages which owned donkeys in the regions. Villages were designated as either "exposed" (had a previously known exposure to an equine non-governmental organisation (NGO) or equine education/research programme), or "unexposed" (a naive population with regards to the above criteria). The Donkey Sanctuary is one of the veterinary NGOs that operate in these regions. Mobile veterinary clinics visit rural villages and provide veterinary and educational interventions aimed at improving the health and welfare of working donkeys. Of the eight villages, four were categorised as "exposed" and four as "unexposed". Participants were eligible for inclusion in the study if they lived within the chosen village and owned or used a donkey. Participation was entirely voluntarily and owners were free to leave the study at any point. Participants were selected for the study using two different methods. In the villages that were exposed, donkey owners were approached during their attendance at the mobile veterinary clinic. Participants from unexposed villages were recruited using development agents assigned from the relevant Bureau of Agriculture. Between January and March 2008, a total of 80 individuals took part in the group PSA, 10 individuals (two groups of five) taking part from each site, whilst a further 40 individuals also took part in individual interviews (five individuals per site).

Study Design: The individual questionnaire and the group PSA (Supplementary Information 2) were conducted in either of two regional dialects (Amharic and Afan Oromo) as dictated by the participant. A trained Ethiopian national, who was fluent in Amharic, Afan Oromo and English, acted as both translator and facilitator. This individual had previous experience in the field of animal health and had received training in 
participatory approaches. The PSA was based on five questions in a semi-structured interview (SSI) format, and utilised a number of different participatory methodologies (Supplementary Information 2). The individual questionnaire and the PSA were piloted with donkey owners from other villages not involved in this study, and questions underwent reverse translation (WHO, 2008) prior to commencing the study. Data were initially translated and recorded in written format by a dedicated recorder in English, and digital photos were taken to record completed matrix boards. Data were entered into a spreadsheet programme (Microsoft Excel 2007, Microsoft Cooperation, USA), which was also used to assist with analysis.

\section{Cross-Sectional Study}

Study Area and Participants: A cross-sectional study was carried out in one of the seven regions of Ethiopia (Oromia). Within this region, one zone (Arsi) was selected based upon: a lack of previous exposure to equine veterinary NGOs; a known high density of donkey users; and, logistical considerations. Within this area, four woredas (administrative departments) (Sire, Hitosa, Tiyo, Degeluna Tijo) were non-randomly selected based on logistical convenience and a complete list of villages within the woredas was obtained from each woreda agricultural office. Thirty-two villages were randomly selected using random numbers generated in a spreadsheet programme (Microsoft Excel 2007, Microsoft Cooperation, USA).

This cross-sectional study was part of a larger study, conducted in November 2008 and July 2009, which needed to minimise contact between participants from different villages (Stringer et al. 2011). Development agents were recruited to liaise with selected villages and to assist in the participant recruitment process. Lists of village inhabitants were obtained from village agricultural offices or municipality offices, and participants in villages were randomly selected using random numbers generated in Microsoft Excel 2007 (Microsoft Cooperation, USA). Participants were eligible for inclusion in the study if they were male, owned or used a donkey, were over 18 years of age, and able to attend the study visits. All participants $(n=516)$ were recruited on a volunteer basis and were free to refuse participation or leave the study at any point. Formal consent was assumed by continued participation in the study after an introduction was administered.

Study Design: Questionnaires were administered on an individual basis by a trained animal health worker (AHW) in either of two regional languages (Afan Oromo and Amharic) in a consistent and controlled manner with no additional clarification. Questionnaires were extensively piloted and reversed translated.

Data Collection: Data collected in this study included participant's knowledge on wounds and wound management in donkeys, information sources utilised and additional demographic information (Supplementary Information 3). Participants' knowledge (knowledge score) was measured using 12 concise questions (described in Stringer et al., 2011), which required participants to volunteer between one and four correct responses per question to achieve a total possible maximum score of 28. The content of this study questionnaire was informed from information gathered during the individual and group PSA discussions (e.g. the grouping of the information sources utilised by participants for information and advice). Data were initially translated and recorded in written format by a dedicated recorder in English. These data were then entered into a spreadsheet programme (Microsoft Excel 2007, Microsoft Cooperation, USA).

Data Analysis: Multilevel multivariable linear regression models were utilised to determine the effect of variables on knowledge score, allowing for clustering of individuals within villages. The outcome measure for this analysis was a continuous variable reflecting a knowledge score on a questionnaire (out of a maximum of 28). Data were analysed using SPSS v20 (SPSS Inc, Chicago, Illinois, USA), MLwiN v2.25 (Centre for Multilevel Modelling, Bristol, UK) and R (http://www.r-project.org). All variables that showed some association with the outcome on univariable analysis ( $p$-value $<0.3$ ) were considered during the building of the final multivariable models. A number of variables (cluster group and individual information sources) were correlated; therefore, separate models were built with each of these variables. Two different models were built to account for the correlation between the cluster group and information source by including these variables as fixed effect variables in the model build. The analysis focused on the cluster group model. The cluster groups were mutually exclusive (i.e. people only belonged to one cluster group) whereas there was likely to be some correlation between information sources (i.e. many people from different cluster groups contacted a specific information source). Models were fit using penalised quasi-likelihood with 2nd 
order Taylor series expansion. A backwards-stepwise process utilising the Hosmer-Lemeshow test statistic was used, with covariates remaining in the model if they were statistically significant (p-value $<0.05$ ), or if they altered the effect of other covariates by greater than $25 \%$. Random coefficients models, allowing the coefficients for fixed effects, including the intervention, to vary across villages (i.e. random slopes), were assessed to determine if the effects varied by villages.

Cluster analysis was used to explore clusters based on participants' responses to which information sources they contacted. Hierarchical cluster analysis allowed the production of graphical outputs, indicating the level of similarity between cluster groups. Data were analysed using R (http://www.r-project.org). Cluster analysis was performed using the binary distance measure and the Ward agglomeration method. Cluster groups were identified by visual inspection of the cluster dendrogram (Supplementary Information 4) and by examination of the distribution of information of sources between the groups when different numbers of groups were selected. The number of clustered groups selected for presentation here was chosen as it most clearly delineated the sources into distinct sets. After group identification, the number of participants in each cluster and the information source they contacted was calculated. A comparison of specific variables (e.g. education level, literacy, animal ownership) was performed across cluster groups using a Chi-square analysis. For one variable, education level, two categories were combined (Higher and Other) due to the small number of responses in one category (Other). This allowed sufficient numbers in each cell to perform analysis.

\section{RESULTS}

Individual Questionnaire and Group Participatory Situation Analysis (PSA): Of the 40 participants in the individual interviews, $72.5 \%$ volunteered that others sought them for information and advice concerning donkey health and husbandry issues, and $85 \%$ of participants indicated that they offered advice freely on the same subjects. In all, participants identified 11 sources they contacted concerning donkey health and husbandry issues across both exposed and unexposed sites (Supplementary Information 5 and 6). The three most frequently volunteered sources of information for owners in exposed and unexposed areas were family, neighbours and the Agricultural Bureau, although patterns of use of these sources varied. There was a reduction in the percentage of owners volunteering the
Agricultural Bureau in exposed sites compared to unexposed sites, but an increase in those who volunteered The Donkey Sanctuary in exposed sites. No owners volunteered The Donkey Sanctuary in unexposed sites. Most owners talked to their family about their donkey on a daily basis, with many owners also talking to their neighbours about their donkey on a daily or weekly basis. The Agricultural Bureau was contacted by owners predominately when their donkey was sick or required treatment. Neighbours were contacted by a greater percentage of owners in unexposed sites for other and sickness/treatment concerns than in exposed sites, where The Donkey Sanctuary was contacted on an 'other' category basis. Private drug sellers and traditional healers were only volunteered in unexposed sites, where The Donkey Sanctuary were not providing veterinary services. In exposed sites, neither of these sources were volunteered.

During the group PSA, participants volunteered nine information sources for information on donkey healthcare, husbandry and work issues (Supplementary Information 6). Owners were also asked how frequently they talked to these sources. Owners were also asked collectively whether they offered advice freely on the same subjects to others, all 16 groups (100\%) responded that they did. The three most frequently volunteered sources of information for owners in exposed areas were: The Donkey Sanctuary, family and the Agricultural Bureau, whilst the three most frequently volunteered sources of information for owners in unexposed areas were the Agricultural Bureau, family and neighbours. There was a reduction in the percentage of owners volunteering the Agricultural Bureau in exposed sites compared to unexposed sites, and The Donkey Sanctuary was only volunteered in exposed sites.

The majority of owners talked to their family about their donkey on a daily basis, with the majority of owners also talking to their neighbours about their donkey on a daily or weekly basis (Supplementary Information 6). The Agricultural Bureau was contacted by owners predominately when their donkey was sick or required treatment.

Cross-Sectional Study: 516 participants were enrolled in the study from four woredas; Sire $(n=131)$, Hitosa $(n=126)$, Tiyo $(n=149)$ and Degluna Tijo $(n=110)$. The most frequently contacted information source was the traditional healer (Table $1 ; 44.2 \%$ ), followed by the Agricultural Office (40.3\%) and Friends/Neighbours 
(29.5\%). Except for the 'Other' information source, there was a significant difference between the knowledge scores of those that contacted and those that didn't..
Knowledge scores were approximately normally distributed and ranged from zero to 13 with a median score of six (from a maximum of 28).

Table 1. Participant response $(n=516)$ and median knowledge scores about whether they contacted a specific information source concerning donkeys and participant's literacy ability and radio access.

\begin{tabular}{|c|c|c|c|c|c|c|c|c|c|c|c|}
\hline \multirow[t]{2}{*}{$\begin{array}{l}\text { Information } \\
\text { Source }\end{array}$} & \multirow{2}{*}{$\begin{array}{l}\mathrm{C} \\
\%\end{array}$} & \multirow{2}{*}{$\begin{array}{c}\text { NC } \\
\%\end{array}$} & \multicolumn{4}{|c|}{$\begin{array}{c}\text { Contact Frequency } \\
(\%)\end{array}$} & \multicolumn{2}{|c|}{$\begin{array}{c}\text { Perceived } \\
\text { Reliability } \\
\text { (\%) }\end{array}$} & \multicolumn{2}{|c|}{$\begin{array}{l}\text { Median } \\
\quad \text { KS }\end{array}$} & \multirow[t]{2}{*}{$\begin{array}{c}\text { Mann Whitney } \\
\text { U (p-value) }\end{array}$} \\
\hline & & & $\mathrm{D}$ & $\mathrm{W}$ & I & 0 & No & Yes & $\mathrm{NC}$ & $\mathrm{C}$ & \\
\hline Family/Elders & 18.8 & 81.2 & 3.5 & 3.3 & 10.5 & 1.6 & 84.7 & 15.3 & 6.00 & 7.00 & 0.04 \\
\hline Friends/NB & 29.5 & 70.5 & 1.6 & 5.2 & 19.6 & 3.1 & 76.4 & 23.6 & 6.00 & 7.00 & $<0.001$ \\
\hline Agri. Office & 40.3 & 59.7 & 0.2 & 2.3 & 10.7 & 27.1 & 61.2 & 38.8 & 6.00 & 7.00 & 0.02 \\
\hline P/K Ass. & 6.2 & 93.8 & 0.2 & 0.8 & 4.3 & 1.0 & 94.2 & 5.8 & 6.00 & 7.00 & 0.02 \\
\hline Trad. Healer & 44.2 & 55.8 & 0.0 & 1.7 & 9.1 & 33.3 & 79.1 & 20.9 & 6.00 & 7.00 & 0.003 \\
\hline Other & 2.5 & 97.5 & 0.0 & 0.0 & 0.0 & 2.5 & 98.1 & 1.9 & 6.00 & 8.00 & 0.06 \\
\hline
\end{tabular}

Key: KS= Knowledge Score, P/K Ass. = Peasant or Kebele Association, NB= Neighbours, Agri. Office = Agricultural Office, Trad. Healer $=$ Traditional Healer, $\mathrm{C}=$ Contacted, $\mathrm{NC}=$ Not Contacted, $\mathrm{D}=$ Daily, $\mathrm{W}=$ Weekly, $\mathrm{I}=$ Irregular, $\mathrm{O}=\mathrm{Other}$.

Over half of the participants $(55.4 \%)$ were literate in Amharic, whilst the majority of participants (78.5\%) were not literate in Afan Oromo (Supplementary Information 7). The majority of participants (80.0\%) were able to listen to the radio on a daily basis. There was a significant difference between the knowledge scores (KS) depending on the literacy of the participants (unable to read Amharic: median KS = 5.00; able to read Amharic, median KS = 7.00, Mann Whitney U p-value <0.001: unable to read Afan Oromo: Median KS $=6.00$; able to read Afan Oromo, median KS $=7.00$, Mann Whitney U p-value $<0.001$ ), and who had radio access, compared to those participants that had no radio access (No radio access: median $\mathrm{KS}=5.00$; radio access, median $\mathrm{KS}=6.50$, Mann Whitney $\mathrm{U}, \mathrm{p}$-value $<0.001)$. The majority of participants $(81.4 \%)$ in the crosssectional survey responded that they sought information on these subjects from at least one source. Contact with these sources was on an irregular and needs basis, most likely seeking information and advice for healthcare and illness concerns.

Based on the results of the cluster analysis using data on information sources, a cut-off was chosen that identified six clusters, C1-6 (Table 2). The largest group of participants $(\mathrm{C} 2, \mathrm{n}=154)$ contacted a mix of sources for information, whilst the smallest cluster $(\mathrm{C} 5, \mathrm{n}=43)$ contacted either the Agricultural Bureau or a Traditional Healer for information. Participants in C2 (mix of sources) had the joint highest median knowledge score, equal to that of $\mathrm{C} 1$ and C5. Participants in C3 ( $\mathrm{n}=132)$ did not contact any sources for information and had the lowest median knowledge score. A number of variables were significantly different across cluster groups, including education level, ability to read Amharic and Afan Oromo, age and knowledge score. The largest percentage of participants in the highest education category were found in cluster two (mix of sources), this cluster also had the lowest illiteracy to Amharic and Afan Oromo. The largest percentage of participants in the lowest education category were found in C3 (no sources). The highest percentage of illiteracy to both Amharic and Afan Oromo were also seen in this cluster. The median age of those in C3 (50.5 years) was over ten years greater than the median age of participants in C2 (40.0 years). Participants in cluster two were the most likely to be sought for advice (35.7\%), whilst also $43.5 \%$ of participants in this cluster said they give advice freely. Participants in C3 were the least likely to be sought for advice $(2.3 \%)$, with only $2.3 \%$ of participants saying they gave advice freely. (Supplementary Information 7 for further information). Only one cluster (C3, n=132) contacted no information sources, whilst the majority of participants in this study $(\mathrm{C} 2, \mathrm{n}=154)$ contacted a number of information sources. A number of variables (cluster and the specific information sources) were highly correlated, as the cluster variable was formed based on the information sources a participant contacted. Therefore, only one variable (cluster) was included in the multilevel multivariable linear regression model. 
Table 2. Sources of information in each cluster.

\begin{tabular}{lcccccccccc}
\hline \multirow{2}{*}{ Cluster } & $\begin{array}{c}\text { No. of parts. } \\
\text { \% (n) }\end{array}$ & $\begin{array}{c}\text { Family and } \\
\text { Elders }\end{array}$ & $\begin{array}{c}\text { Friends } \\
\text { and NB }\end{array}$ & AB & $\begin{array}{c}\text { PA/Keb } \\
\text { Ass. }\end{array}$ & Trad & Other & Cluster Des. \# & Med. KS & IQR \\
\hline C1 & $9.7(50)$ & 0 & 100 & 0 & 0 & 52 & 0 & Fri/NB /Trad & 7.0 & 3.6 \\
C2 & $29.8(154)$ & 63 & 66 & 61 & 21 & 60 & 8 & Mix & 7.0 & 3.5 \\
C3 & $25.6(132)$ & 0 & 0 & 0 & 0 & 0 & 0 & None & 5.8 & 3.0 \\
C4 & $13.8(71)$ & 0 & 0 & 100 & 0 & 0 & 0 & AB only & 6.0 & 4.0 \\
C5 & $8.3(43)$ & 0 & 0 & 100 & 0 & 100 & 0 & AB/Trad & 7.0 & 3.0 \\
C6 & $12.8(66)$ & 0 & 0 & 0 & 0 & 100 & 0 & Trad only & 6.0 & 2.0 \\
\hline
\end{tabular}

Key: No. of parts $=$ Number of participants, $\mathrm{NB}=$ Neighbours, $\mathrm{AB}=$ Agricultural Bureau, PA/Keb $=$ Peasant $/$ Kebele Association, Trad. $=$ Traditional Healer, Med. KS = Median Knowledge Score, IQR = Interquartile range.

\# Cluster descriptions identify the main information sources within each cluster.

Univariable analysis of variables associated with knowledge score is presented in Supplementary Information 8. Model 1 considered the effect of cluster group as a fixed effect variable on knowledge score, after excluding information source as a variable for consideration (Table 3). The final variables that had a significant effect on the outcome variable (knowledge score) were formal education level, cattle ownership, whether a participant gives advice and washes and cleans wounds on his donkey. Cluster groups did not have a significant effect on the outcome variable in the final model. Due to the association between education level and cluster group, model 2 was considered. In model 2 , the education level variable was not included and the cluster group variable forced in as a fixed effect. Without the education level variable in the model, the cluster group variable was significantly associated with the outcome variable.

Table 3. Multilevel, multivariable linear regression model showing variables that influence owner knowledge score. The outcome variable was the knowledge score (a continuous score with a maximum of 28).

\begin{tabular}{|c|c|c|c|c|c|c|c|}
\hline \multirow{2}{*}{ Variable } & & \multicolumn{3}{|c|}{ Model 1} & \multicolumn{3}{|c|}{ Model 2} \\
\hline & & Coeff & SE & P-value & Coeff & SE & P-value \\
\hline \multirow[t]{5}{*}{ Formal Education } & No Education & \multicolumn{3}{|c|}{ Ref } & & & \\
\hline & Adult Education & 0.827 & 0.296 & \multirow{4}{*}{$<0.001$} & & & \\
\hline & Primary & 1.550 & 0.240 & & & & \\
\hline & Junior & 2.144 & 0.304 & & & & \\
\hline & Higher & 2.732 & 0.307 & & & & \\
\hline \multirow[t]{2}{*}{ Own Cattle } & No & \multicolumn{3}{|c|}{ Ref } & \multicolumn{3}{|c|}{ Ref } \\
\hline & Yes & 0.961 & 0.369 & 0.009 & 1.334 & 0.396 & $<0.001$ \\
\hline \multirow[t]{2}{*}{ Give Advice } & No & \multicolumn{3}{|c|}{ Ref } & \multicolumn{3}{|c|}{ Ref } \\
\hline & Yes & 0.644 & 0.225 & 0.004 & 0.598 & 0.269 & 0.03 \\
\hline \multirow[t]{2}{*}{ Wash + Clean Wounds } & No & \multicolumn{3}{|c|}{ Ref } & \multicolumn{3}{|c|}{ Ref } \\
\hline & Yes & 0.415 & 0.184 & 0.02 & 0.394 & 0.203 & 0.05 \\
\hline \multirow[t]{6}{*}{ Cluster } & $\mathrm{C} 3$ & & & & \multicolumn{3}{|c|}{ Ref } \\
\hline & $\mathrm{C} 1$ & & & & 0.897 & 0.391 & \\
\hline & $\mathrm{C} 2$ & & & & 1.016 & 0.288 & \\
\hline & $\mathrm{C} 4$ & & & & 0.336 & 0.328 & 0.02 \\
\hline & $\mathrm{C} 5$ & & & & 0.714 & 0.392 & \\
\hline & C6 & & & & 0.362 & 0.332 & \\
\hline
\end{tabular}

Coeff $=$ Coefficient 


\section{DISCUSSION}

Animal owners seek information from any number of sources to aid decision making to improve the health and productivity of their animals (Mbanda-Obura et al.. 2017). Van den Ban and Hawkins, (1996) identified that informal communication networks, such as those with friends and neighbours, are an especially important source of information, with Granovetter (1973) arguing that weak ties, people loosely connected to others in the network, are necessary for diffusion to occur across subgroups within a system. Participants in this study volunteered numerous sources of information regarding health and husbandry advice for donkeys. These included friends, family and neighbours, likely to represent strong ties, and those such as the government agricultural bureau, private veterinary surgeons and external veterinary NGOs, likely to represent weak ties. The findings in our study are supported by Sseguya et al. (2012) and Mbanda-Obura et al. (2017), in which rural community members in Uganda and Kenya accessed information on a range of rural issues from an array of sources. Kenyan smallholders listed family, neighbours and friends as network members, with friends being people the respondent 'like to discuss issues of farming with' (Hogset, 2005). Whilst Mbanda-Obura et al. (2017) identified that the most important sources for farmers included fellow farmers due to proximity and perceived risk. Tesfaye et al. (2005) identified that Contact Farmers and 'better-informed farmers' living in the neighbourhood were found to be important sources of information for other farmers, with farmers meeting each other regularly during social events allowing the discussion of agricultural technology. In our study, the frequency of contact differed between the volunteered information sources and is likely to be a result of the differing information sought from each source, and the availability of access to each source.

Our study identified a reduction in owners who volunteered the agricultural bureau as a source of information when there was access to an external veterinary NGO. This is potentially due to the increased reliability owners perceive in NGOs, as demonstrated by Sseguya et al. (2012), where NGOs were rated highly by communities because of their timeliness, good quality and regular follow up when compared to governmental departments. It may also be a result of the NGO services being offered at no cost to owners. Very few owners volunteered the 'private' veterinary/pharmacy information source, and only volunteered it when their donkey was sick or needed treatment.

Owners responded that the private drug sellers were only interested in making money and sometimes sold out of date and ineffective drugs. This finding is consistent with Sseguya et al. (2012), who identified that information from private businesses was rated low in terms of reliability, as sellers tended to supply fake products and were keen to gain bigger profit margins. The provision of free services by an NGO has the potential to create a dependency on free services, undermine local service providers and disrupt local farmer-to-farmer exchange systems (Pritchard, 2010; Seboka \& Deressa, 1999).

The majority (80.0\%) of owners in our study had access to radios on a daily basis, although we did not ascertain whether owners used this as a source of information. The level of radio access was higher than the $49 \%$ of individuals that owned radios in the study by Tesfaye et al. (2005). The differences in these studies might be due to more people accessing radio programmes than owning radios, with individuals often listening to a communal or family radio rather than owning a radio individually. Radio programmes have been used to effectively communicate information (Mbanda-Obura et al., 2017, De Silva \& Garforth, 1997; Valente et al., 1994), and have the potential to be a useful source of information for farmers in this region. A number of indigenous social networks exist in rural Ethiopia, including the important traditional institution, Edir, which serves as a platform for members to inform each other about recent development and other emerging issues in farming and social affairs (Seboka \& Deressa, 1999).

Tesfaye et al. (2005), identified that the majority of farmers (94\%) were members of at least one social institution, and this has been suggested as one possible route for the dissemination of agricultural interventions. Farmer groups have also been recommended for the dissemination of information (Worku, 2017; Davis et al., 2004). Information was only sought by $6 \%$ of owners from Peasant/Kebele Association in our study with the majority of owners (94\%) reporting this information was not reliable. Our study did not try to identify whether owners sought information from other social institutions or farmer groups, nor whether they more frequently used the Peasant/Kebele Association for other agricultural issues.

The participants in our study were all rural donkey owners, and the villages and the owners who participated 
thought to be representative of other rural villages and working donkey owners in the region. However, there is potential for selection bias as no random sampling process was utilised to select either the villages or owners in the individual questionnaire and PSA studies, and owners who volunteered to participate in these studies may differ in some way from those who did not want to participate. Both of these issues could potentially lead to the villages and owners being a non-representative sample of the intended target population. In the crosssectional study, both villages and animal owners were randomly selected and are therefore more likely to be representative of other rural donkey owners in the region.

For participants in our study seeking information, only $21 \%$ thought that the advice they received from the traditional healer, the most frequently contacted information source, was reliable, whereas $39 \%$ of participants thought the agricultural bureau, the second most frequently contacted information source was reliable. Tesfaye et al. (2005), identified that farmers facing problems relating to agriculture consulted extension agents first for advice and information, and approximately $80 \%$ were satisfied with the services provided. Whilst our study reveals comparable results to Tesfaye et al. (2005), with regards to information sources contacted, there was a difference in the perceived reliability of sources. The perceived low reliability of the information provided highlights the real concern of owners, as the most important criteria for farmers with regards to information supply is likely to be reliability and accuracy (Ong'ayo et al., 2016; Tesfaye et al., 2005). Sseguya et al., (2012) stated that the reliability of information goes hand in hand with its application, with most of the information that was perceived as unreliable also being reported as difficult to apply. The quality and relevance of information and technology to a farmer's current need influences perceptions towards extension service delivery systems (Ong'ayo et al., 2016).

Cluster analysis of the participants suggested six clusters, each representing a type of individual based on those that seek different information sources. All clusters, except one, contacted at least one source for information regarding donkey health and husbandry. Given the low status of the donkey within Ethiopian communities and the lack of healthcare provided for them, it is unlikely that farmers in this study cluster together as a result of their knowledge on wounds and wound management in donkeys. Valente (1997) looking at contraceptive use in Cameroonian women, demonstrated that 'birds of a feather flock together', in that women cluster in networks with others like themselves (with regards to age, education level and wealth). Therefore, a more likely explanation in our study was that farmers were in clusters with individuals who were more similar to each other as a result of other demographic characteristics, such as education level or cattle ownership, rather than their knowledge concerning donkey healthcare. Knowledge score in our study increased in clusters that contained more information sources, and seeking information from multiple sources was associated with greater knowledge. Our study did not attempt to validate the content or quality of the information provided by each information source. Hence, with regards to knowledge score, it may be that specific sources were important, or that there was something different about individuals who seek information or seek it more widely.

Age, education level, and gender of the household head are just some of the important factors associated with agricultural technology adoption decisions (MbandaObura et al. 2017; Nguthi, 2008; Tesfaye et al. 2005). Mbanda-Obura et al. (2017) identified that gender, age, education, farming experience and farm size significantly influenced access to agricultural information sources; whilst age, education, farm size and farming experience significantly influenced the choice of pathways. Younger individuals may be more knowledgeable about newer practices and more willing to bear risk, however, older individuals have more experience, resources and authority allowing them to engage with agricultural adoption (Nguthi, 2008). In our study, we found that older participants had lower knowledge scores, and that knowledge score increased as education level increased. An understanding of the education level of the intended recipients is important when designing and developing appropriate pathways for any technology transfer or dissemination (Mbanda-Obura et al., 2017; Tesfaye et al., 2005). Educated farmers are said to be early adopters of technology, with education potentially making farmers more receptive to technical recommendations that require a certain level of literacy (Nguthi, 2008). Weir \& Knight (2000) found that household-level education is important to the timing of adoption, with educated farmers being early innovators, providing a better example, which may be copied by less-educated farmers. Educated farmers are also better able to copy those who 
innovate first, enhancing the diffusion of new technology. A previous study in central Ethiopia found that $23 \%$ of household heads had learned to read and write through informal sources (adult education programmes), whilst $38 \%$ of household heads had undergone formal education (primary education or greater). Tesfaye et al. (2005) also revealed that $39 \%$ of household heads have never received any education as a result of economic, cultural and institutional problems. In our study, only $14 \%$ of individuals had received an adult education programme, $61 \%$ of individuals had undergone formal education (primary level or greater), and $25 \%$ of individuals had never received any education. This increase in formal education amongst household heads is more likely to be due to differences in the geographical locations of the two studies rather than a chronological effect. Therefore, any recent changes in education would be unlikely to have filtered through to household heads. If education levels vary geographically, there is a need to carefully consider the utilisation of different interventions in different areas. An association between age, education level, illiteracy and the transfer, adoption and use of agricultural technologies in Ethiopian farmers has been previously demonstrated (Mbanda-Obura et al., 2017; Tesfaye et al., 2005), with other studies concluding that the level of education of the household head has a positive association with the level of intervention adoption (Asfaw 1997, cited by Tesfaye et al., 2005). Socioeconomic status was seen to play a role in access to agricultural extension services in one study by Mogues et al. (2009), with bettereducated farmers more likely to receive visits from extension agents, and a greater proportion of literate farmers attending extension meetings than illiterate farmers. Yohannes et al. (1990) demonstrated that the impact of education on Ethiopian farmers on the probability of adoption of agricultural practices was substantial. Households with some level of education are more likely to adopt technologies than those with none (Tesfaye et al., 2005), with Weir \& Knight (2000) concluding that household-level education is important to the timing of adoption.

Livestock ownership has been used to represent wealth, and it is regularly hypothesized that the adoption of agricultural technologies requires sufficient financial wellbeing (Knowler \& Bradshaw, 2007). In the study by Tesfaye et al. (2005), 99\% of rural donkeys owners kept cattle, which is comparable to our study where $94 \%$ of donkey owners also owned cattle. The significance between cattle ownership and increased knowledge score in our study might be explained by the fact that individuals who own cattle may be wealthier, and may also know more about general animal healthcare. That individuals that already wash and clean wounds on their donkeys had an increased knowledge score may reflect reverse-causality, with this behaviour being due to the greater level of knowledge.

\section{CONCLUSION AND RECOMMENDATIONS}

Participants in this study contacted numerous sources for information about donkey health and husbandry issues. The main sources contacted were: traditional healers, governmental agricultural offices and friends/neighbours. Sources were contacted on a predominately irregular basis and were largely deemed to be unreliable with regards to the information they provided. Emphasis should be given to recognising farmers as knowledge generators and not only as passive knowledge recipients (Worku, 2017), with a further commitment to agricultural extension services that are demand driven, not supply driven, and focused on the needs and problems of smallholder farmers (Agitew et al., 2018; Elias et al., 2015). A number of variables were associated with knowledge score, including sources of information, cluster group and educational level. It may be necessary to use different sources and channels to transfer and disseminate information to individuals living in rural Ethiopia. The relationship between specific farmer variables and animal health knowledge is complex and further work is required to fully understand possible casual pathways.

Acknowledgements: The authors would like to thank the staff at both SPANA and The Donkey Sanctuary (UK and Ethiopia) for their assistance and also the College of Veterinary Medicine and Agriculture, Addis Ababa University for their cooperation. The authors also thank all the participants and development agents who were involved in this study, and are grateful to the Welcome Trust Livestock for Life grant awarded to Dr. Gina Pinchbeck for the funding of this project.

\section{REFERENCES}

Agitew, G., Yehuala, S., Demissie, A., Dagnew, A. (2018). Technology gaps of agricultural extension: Mismatch between demand and supply in North Gondor zone, Ethiopia. Journal of Agricultural Extension and Rural Development. 10(8), 144-149.

Belay, K., Degnet, A. (2004). Challenges Facing Agricultural Extension Agents: A Case Study from 
South-Western Ethiopia. African Development Review 16 (1), 139-68.

Curran, M.M., Feseha, G., and Smith, D.G. (2005). The Impact of Access to Animal Health Services on Donkey Health and Livelihoods in Ethiopia.Tropical Animal Health and Production 37(1), 47-65.

David, M.M., Samuel, H.S. (2014). The role of agricutlure extension in the 21st century: Reflections from Africa. International Journal of Agricultural Extension. 02(01), 89-93.

Davis, K., Franzel, S., Hildebrand, P., Irani, T., Place, N. (2004). Extending technologies among small-scale farmers in Meru, Kenya: Ingredients for success in farmer groups. The Journal of Agricultural Education and Extension. 10, 53-62.

de Silva, D.N., Garforth, C. (1997). The effectiveness of different radio programme formats for the dissemination of information on the safe use of insecticides in paddy cultivation in Mahaweli system-C of Sri Lanka. Tropical Agricultural Research. 9, 302-316.

Elias, A., Nohmi, M., Yasunobu, K., Ishida, A. (2015). Farmers' satisfaction with agricultural extension service and its influencing factors: A case study in North West Ethiopia. Journal of Agricultural Science and Technology. 18, 39-53.

FAO. (2016). FAOSTAT website. Available: http://www.fao.org/faostat/en/\#home Accessed: 2018 Jan 16.

Granovetter, M. (1973). The strength of weak ties. American Journal of Sociology. 78, 1360-1380.

Hogset, H. (2005). Social Networks and Technology Adoption. Paper Presentation: American Agricultural Economics Association Annual Meeting.

Kassa, B. (2003). Agricultural. Extension in Ethiopia: The Case of Participatory Demonstration And Ttraining Extension System. Journal of Social Development in Africa 49(4), 105-16.

Knowler, D., Bradshaw, B. (2007). Farmers' adoption of conservation agriculture: A review and synthesis of recent research. Food Policy. 32, 25-48.

Krishnan, P,. Patnam, M. (2014). Neighbors and Extension Agents in Ethiopia: Who Matters More for Technology Adoption? American Journal of Agricultural Economics 96(1), 308-27.

Mbada-Obura, S., Tabu, I.M., Amudavi, D.M., Obura, R.K.
(2017). Deteriminants of choice of agricultural infomration sources and pathways among sorghum farmers in Ndhiwa sub-county, western Kenya. International Jpurnal of Agricultural Extension. 05(01), 39-49.

Tewodaj, M., Cohen, M., Birner, R., Lemma, M., Tadesse, F., Paulos, Z. (2009). Agricultural Extension in Ethiopia through a Gender and Governance Lens.

Msuya, C.P., Annor-Frempong, F.K., Magheni, M.N., Agunga, R., Igodan, C.O., Ladele, A.A., Huhela, K., Tselaesele, N.M., Msatilomo, H., Chowa, C., Zwane, E., Miiro, R., Bukeyn, C., Kima, L.A., Meliko, M., Ndiaye, A. (2017). The role of agricutural extension in Africa's devleopemnt, the importance of extension workers and the need for change. International Journal of Agricutural Extension, 05 (01), 59-70.

Nguthi, F.N. (2008). Adoption of agricultural innovations by smallholder farmers in the context of HIV/AIDS: The case of tissue-cultured banana in Kenya. Wageningen Academic Publishers. The Netherlands.

https://www.wageningenacademic.com/doi/boo $\mathrm{k} / 10.3920 / 978-90-8686-641-0$

Ong'ayo, A.H., Onyango, C.A., Ochola, W.W. (2016). Smallscale farmers' perceptions towards demand driven system of agricultural extension service delivery. Case study of Siaya and Kilifi counties in Kenya. International Journal of Agricultural Extension. 04(01), 01-09.

Pearson, R A., M Alemayehu, Tesfaye, A., Allan, E. F., Smith, D.G., Asfaw, M. (2001). Use and Management of Donkeys in Peri-Urban Areas of Ethiopia. University of Edinburgh. https://www.gov.uk/dfid-research-outputs/useand-management-of-donkeys-in-peri-urbanareas-of-ethiopia-phase-one-133-pp.

Pritchard, J C., Lindberg, A.C., Main, D.C.J., Whay, H.R. (2005). Assessment of the Welfare of Working Horses, Mules and Donkeys, Using Health and Behaviour Parameters. Preventive Veterinary Medicine 69 (3-4), 265-83.

Pritchard, J. C. (2010). Animal Traction and Transport in the 21st Century: Getting the Priorities Right. Veterinary Journal, 186 (3), 271-74.

Seboka, B., Deressa, A. (1999). Validating farmers' indigenous social networks for local seed supply in central rift valley of Ethiopia. The Journal of 
Agricultural Education and Extension. 6, 245-254.

Sseguya, H., Mazur, R., Abbott, E., Matsiko, F. (2012). Information and communication for rural innovation and development: context, quality and priorities in Southeast Uganda. The Journal of Agricultural Education and Extension, 18, 55-70.

Stringer, A.P., Christley, R.M., Bell, C.E., Gebreab, F., Tefera, G., Reed, K., Trawford, A., Pinchbeck, G.L. (2017). Owner Reported Diseases of Working Equids in Central Ethiopia. Equine Veterinary Journal 49(4), 501-6.

Stringer, A.P., Bell, C.E., Christley, R.M., Gebreab, F., Tefera, G., Reed, K., Trawford, A., Pinchbeck, G.L. (2011). A Cluster-Randomised Controlled Trial to Compare the Effectiveness of Different Knowledge-Transfer Interventions for Rural Working Equid Users in Ethiopia. Preventive Veterinary Medicine 100, 9099.

Tesfaye, A., Jemal, I., Ferede, S., Martin Curran, M. (2005). Technology Transfer Pathways and Livelihood Impact Indicators in Central Ethiopia. Tropical Animal Health and Production 37, 1, 101-22.

Valente, T.W., Watkins, S.C., Jato, M.N., Van der Straten, A., Tsitsol, L.M. (1997). Social network associations with contraceptive use among Cameroonian women in voluntary associations. Social Science and Medicine. 45, 677-687.

Valente, T.W., Kim, Y.M., Lettenmaier, C., Glass, W., Valente, B.T.W. (1994). Radio Promotion of Family
Planning in the Gambia. International Family Planning Perspectives. 20, 96-100.

Van den Ban, A.W., Hawkins, H. (1996). Agricultural Extension. Blackwell Science Ltd.

Edilegnaw, W., Yalew, A. (2007). Farmers' Variety Attribute Preferences: Implications for Breeding Priority Setting and Agricultural Extension Policy in Ethiopia. African Development Review 19(2), 379-96.

Weir, S., Knight, J. (2000). Adoption and Diffusion of Agricultural Innovations in Ethiopia: The Role of Education. Economic Development and Cultural Change, 53, 93-113.

WHO. (2008). A Guide to Developing Knowledge, Attitude and Practice Surveys. World Health Organisation, 1-68. https://doi.org/Advocacy, communication and social mobilization for TB control: a guide to developing knowledge, attitude and practice surveys. WHO/HTM/STB/2008.46.

Worku, A.A. (2017). The effectiveness of farmers research group approach in potato technology dissemination and adoption case study of western part of Ethiopia. Internaional Journal of Agricutural Extension. 05 (02), 43-49.

Yohannes, K., Gunjal, K., Coffin, G. (1990). Adoption of New Technologies in Ethiopian Agriculture: The Case of Tegulet-Bulga District, Shoa Province. Agricultural Economics, 4, 27-43. 